\title{
CONJUNTURA DA APROVAÇÃO DA LEI 13.467/2017 -A REFORMA TRABALHISTA NO BRASIL
}

\author{
CONJUNCTURE OF LAW APPROVAL 13.467 / 2017 - THE LABOR REFORM IN BRAZIL
}

\section{Camila Escorsin Scheifer}

Doutoranda no Programa de Pós-Graduação em Ciências Sociais Aplicadas, Mestre em Ciências Sociais Aplicadas e Bacharel em Direito pela Universidade Estadual de Ponta Grossa - UEPG. Ponta Grossa - Paraná - Brasil.

E-mail: cscheifer@hotmail.com

\section{Silvana Souza Netto Mandalozzo}

Mestre e Doutora em Direito pela Universidade Federal do Paraná - UFPR. Professora Associada do Departamento de Direito das Relações Sociais, do Curso de Direito e do Mestrado e Doutorado em Ciências Sociais Aplicadas da Universidade Estadual de Ponta Grossa - UEPG. Ponta Grossa - Paraná - Brasil. E-mail: smandalozzo@uol.com.br

Recebido em: 17/07/2018

Aprovado em: 27/06/2019

RESUMO: O objetivo deste artigo é apresentar uma breve análise da conjuntura política e econômica na qual se efetivou a aprovação da Lei 13.467/2017, que promoveu a reforma trabalhista no Brasil. Analisando alguns aspectos anteriores, fatores exógenos e os principais atores envolvidos, pretende-se demonstrar a correlação de forças existentes em tal acontecimento. Muito se discutiu, à época, sobre a real necessidade da reforma, considerando o cenário de crise política e econômica que o país enfrentava desde o ano de 2014. Frente aos dados apresentados, almeja levantar questionamentos sobre a polêmica medida, porém sem pretensão de esgotar o tema em razão de sua complexidade e amplitude. Para atingir o objetivo pretendido, realizou-se uma pesquisa de natureza exploratória, utilizando o procedimento metodológico da análise de conjuntura, a pesquisa documental e bibliográfica e, para a análise dos dados, o método indutivo.

Palavras-chave: Reforma Trabalhista. Análise de Conjuntura. Lei 13.467/2017. Direito do trabalho.

ABSTRACT:The purpose of this article is to present a brief analysis of the political and
economic conjuncture in which the approval of Law 13467/2017, which promoted the labor
reform in Brazil. Analyzing some previous aspects, exogenous factors and the main actors
involved, it is intended to demonstrate the correlation of existing forces in such an event. Much
was discussed, at the time, about the real need for reform, considering the scenario of political
and economic crisis that the country faced since the year 2014. Front of the data presented, it
aims to raise questions about the controversial measure, but without pretension to exhaust the
theme because of your complexity and range. In order to achieve the intended objective, a
research of an exploratory nature was carried out, using the methodological procedure of the 
conjuncture analysis, the documentary and bibliographic research and, for data analysis, the inductive method.

Keywords: Labor reform. Analysis of Conjuncture. Law 13.467/2017. Labor law.

SUMÁRIO: Introdução; 1. Conceituando análise de conjuntura 2. Relacionando conjuntura e estrutura 3. O acontecimento: a aprovação da Lei 13.467/2017; 4. Cenário: o Congresso Nacional; 5. Aspectos Anteriores; 6. Fatores exógenos; 7. Atores; 8. Correlação de forças; Conclusão.

\section{INTRODUÇÃO}

A Lei Ordinária 13.467/2017,conhecida como lei da reforma trabalhista,aprovada no pelo Congresso Nacionaldia 11 de julho de 2017 e sancionada dia 13 do mesmo mês, pelopresidente da República, Michel Temer (PMDB), acarretouuma verdadeira revolução nas disposições, princípios e regulações das relações de trabalho vigentes até então no ordenamento jurídico nacional. A alteração de mais de cem pontos da Consolidação das Leis do Trabalho (CLT),em um total de 420 dispositivos, entre artigos, incisos e parágrafos, produziumudançascom um forte contorno neoliberal.Tal reforma acompanha um movimento antigo e global de desregulamentação das normas trabalhistas e de redução do manto protetor do Estado nas relações de trabalho, privilegiando a negociação direta entre empregados e empregadores,enfraquecendo a capacidade de atuação e participação dos sindicatos. No caso brasileiro,ocorreu inclusive uma redução no poder de atuação da Justiça do Trabalho.

Em períodos de forte crise econômica, como a experimentada pelo país a partir do ano de 2014, com queda acentuada do PIB e aumento severo do desemprego,as discussões envolvendo reajustes e reestruturação econômica, bem como as pautas que envolvem flexibilização e retirada de direitos trabalhistas, ganham espaço na agenda política dos governos. O receituário neoliberal e a reestruturação produtiva emergem, a partir da década de 1970, como uma resposta do capitalismo à crise de superprodução que atingiu os países centrais e se espalhou ao redor de todo mundo, até os dias de hoje, com seus efeitos mais nefastos atingindo duramente o mercado de trabalho há pelo menos 40 anos.

A relevância social desta pesquisa está na repercussãode seus efeitos e no impacto social que as mudanças promovidas pela reforma trazem para milhares de brasileiros, assalariados, desempregados, autônomos, terceirizados, precarizados, desalentados. Souza (2009) discorre sobre a necessidade de se estudar os acontecimentos que adquirem um sentido especial para um país, como é o caso da aprovação da Lei 13.467/2017, e apresenta um instrumento metodológico, denominado análise de conjuntura. Tal instrumento visa auxiliar na compreensão de um dado problema, permitindo descobrira "inter-relação ou a correlação de forças existente entre os agentes ou atores políticos, institucionais, econômicos e sociais em um dado acontecimento" (QUEIROZ, 2015, p. 9).

No Brasil, as discussões envolvendo a flexibilização dos direitos trabalhistas e a necessidade de modernização/alterações nas normas da CLT emergem durante a década de 1990, entretanto, uma medida capaz de promovertão aguda e profunda transformaçãonão havia encontrado um cenário propício para acontecer antes de 2017. Questiona-se, então, o que acontecia no país neste período que permitiu a abertura das discussões e propiciou a aprovação de maneira tão rápida destareforma? Qual era a conjuntura em que o país se encontrava e como se apresentava a correlação de forças entre a base do governo e a oposição? Estes e outros questionamentos movem esta pesquisa, que almeja apresentar o tema e levantar questões para discussão, sem objetivar, contudo, esgotá-lo em razão de sua amplitude e complexidade. 


\section{CONCEITUANDO ANÁLISE DE CONJUNTURA}

Herbert de Souza (2009) apresenta a análise de conjuntura como um instrumento metodológico que permite realizar, a partir de critérios objetivos,uma leitura especial da realidade: "uma análise de conjuntura é um retrato dinâmico de uma realidade e não uma simples descrição de fatos ocorridos em um determinado local e período" (ALVES, 2008, p. 1). Utilizando-se da combinação de diversas técnicas de pesquisa, busca "compreender e prognosticar o comportamento dos atores em variadas arenas, num dado instante de tempo" (OLIVEIRA, 2014, p.24). É realizada a partir de um "conjunto de informações contextualizadas historicamente, que consideram aspectos econômicos, sociais, culturais, políticos e tecnológicos locais, nacionais e internacionais"(QUEIROZ, 2015, p. 9). Seu principal objetivo é encontrar respostas para questionamentos sobre a força real dos atores sociais, das classes e seus interesses, sobre os objetivos que os movem e os interesses históricos e imediatos que estão em jogo e, ainda, sobre quais são as regras do jogo, de modo a permitir prognosticar o comportamento dos atores e projetar as frentes de ação.

É de suma importância para o sucesso de uma análise de conjuntura, compreender os antecedentes históricos do acontecimento objeto da investigação, pois eles estão relacionados ao ambiente histórico, à situação política, econômica e social do período que pretendemos analisar. Assim, deve-se buscar realizar uma análise da evolução dos fatos e sua leitura dentro do quadro espaço-temporal definido, afinal, eles não se dão no vazio, "têm relação com a história, com o passado, com as relações sociais, econômicas e políticas estabelecidas ao longo de um processo mais longo" (SOUZA, 2009, p. 14).

Conforme apontado por Queiroz (2015, p. 19), para que seja possível compreender e analisar uma conjuntura, o pesquisador deve valer-se de um método concreto e objetivo, "que consista num processo com etapas que devem ser executadas para alcançar o objetivo pretendido". O autor apresenta algumas categorias capazes de auxiliar neste processo, tais como definir o acontecimento; descrever o cenário ou palco onde os acontecimentos se dão; encontrar e categorizar os atores que participam do processo, bem como a relação de forças existente entre eles; relacionar a conjuntura com a estrutura, e, por fim, aborda a necessidade de se projetar tendências avaliando riscos e oportunidades. Pode-se encontrar alguns modelos propostos de metodologia para a realização da análise de conjuntura, que se resumem, basicamente em seis passos e apresentam as mesmas categorias de análise(QUEIROZ, 2015).

O primeiro passo é a definição do objeto e do propósito da investigação, ou seja, a delimitação do acontecimento que será estudado e dos objetivos da análise (se ela será econômica, política, etc.). Um segundo momento refere-se a coleta de material empírico, das notícias, de informações e dos dados que estão relacionados ao acontecimento estudado. Posteriormente, é essencial procederà listagem e classificação dos acontecimentos, hierarquizando os mais importantes e verificando a relação entre eles, seus principais efeitos e extensão, bem como identificar o palco/cenário e o clima dos acontecimentos. Também é necessário identificar os atores e avaliar as relações de força, ou seja, o poder de influência de cada um no acontecimento. Ao final de todas estas etapas é possível projetar tendências, umdosprincipais objetivos da análise de conjuntura, e que permite a tomada de decisões que permitampara empreender ações concretas e modificar os rumos dos acontecimentos (QUEIROZ, 2015).

Convém ressaltar, conforme adverte Souza (2009),que umaanálise de conjuntura nunca é neutra ou desinteressada, pois se fazsempre em razão de alguma necessidade ou interesse. Tal análise está pautada, na maioria das vezes, em uma certa visão predeterminada do sentido dos acontecimentos: "ela expressa um esforço de compreensão de uma determinada realidade, mas sempre pressupõe um posicionamento assumido previamente" (SILVA, 2014, p. 305). Ainda 
assim, ela deve ser clara e objetiva, respeitando os procedimentos metodológicos e observando a totalidade dos acontecimentos, "ou seja, não poderá privilegiar ou escamotear um ou outro elemento da conjuntura, por mais importante ou incômodo que seja" (SILVA, 2014, p. 306).

Até aqui o que se objetivou foi uma sucinta apresentação da metodologia que norteia esta pesquisa envolvendo o acontecimento reforma trabalhista. No decorrer dos próximos tópicos, será retomada a conceituação de algumas das categorias utilizadas para a análise, relacionando-as ao objeto desta análise.

\section{RELACIONANDO CONJUNTURA E ESTRUTURA}

A estrutura, de acordo com Luiz Eduardo Prates da Silva (2014, p. 306) "refere-se às determinações econômicas, políticas e culturais de cada formação social, caracterizados pelo modo de produção". Ou seja, está relacionada com a forma como a sociedade se organiza, com a maneira como produz os meios essenciais à sua existência. Há pelo menos 500 anos a sociedade na qual vivemos é organizada em torno do modo de produção capitalista, sistema no qual, poucas pessoas detém os meios de produção e outras muitas possuem apenas sua força de trabalho. Queiroz (2015, p.12) conceitua tal sistema como sendo aquele que "é formado pela economia de mercado, tem por princípios a livre iniciativa e a livre concorrência, é globalizado e tem por objetivo a competitividade e o lucro". Esta é a estrutura social que está por trás de toda e qualquer conjuntura atual. A estrutura possui um caráter mais duradouro e permanente, diferentemente da conjuntura, que é mais dinâmica e pode sofrer inúmeras modificações, inclusive em um curto espaço de tempo. (SOUZA, 2009).

O mundo do trabalho vem sofrendo profundas transformações nos últimos 40 anos, impulsionadas pela mundialização do capital, fenômeno também conhecido por globalização. Trata-se de uma nova etapa do desenvolvimento do capitalismo, de um novo regime de acumulação, que emerge a partir da crise de superprodução experimentada durante a década de 1970. Esta nova etapa é marcada por uma forte ofensiva do capital sobre o trabalho que, objetivando recuperar suas margens de lucro e de valorização, reinventa-se e passa a desenvolver e aplicar, em escala global, o complexo de reestruturação produtiva e, principalmente, as políticas neoliberais.(ALVES, 1999).A reforma trabalhista promovidaem 2017 no Brasil estaria em perfeita consonância com o que já vem ocorrendo ao redor de quase todo o mundo nos últimos 40 anos, acompanhando os ditames da reestruturação produtiva, da acumulação flexível e da agenda neoliberal, palavras de ordem para reerguer o capitalismo após a crise da década de 1970.

No debate envolvendo a necessidade ou não da reforma em 2017, o principal argumento utilizado era o da modernização da lei, que estaria velha e ultrapassada, em razão do tempo emque havia sido publicada, afirmando-se que o país já não é o mesmo de 74 anos atrás. Porém, aCLT, criada pelo Decreto-lei 5.452 e sancionada no dia $1^{\circ}$ de maio de 1943 , pelo presidente Getúlio Vargas, durante o Estado Novo, já havia sofrido diversas modificações, ao longo dos seus mais de 70 anos. Um estudo realizado pelo jurista, juizdo trabalho e professor de Direito da Universidade de São Paulo (USP), Jorge Luiz Souto Maior, e publicado em seu blog em 27 de março de 2017, na postagem intitulada "A CLT é velha" aponta que, dos "921 artigos que constavam da CLT, em 1943, somente 625 diziam respeito aos direitos trabalhistas propriamente ditos, pois os demais regulavam o processo do trabalho", e que destes "apenas 255 não foram revogados ou alterados total ou parcialmente de maneira expressa por leis posteriores" (SOUTO MAIOR, 2017a).

Convém salientar, que o Direito do Trabalho não é regulado apenas pela CLT, existem diversas outras fontes, normas, princípios e leis que o regulam, bem como as Súmulas e Orientações Jurisprudenciais oriundas dos tribunais trabalhistas,que contribuem paraa interpretação e aplicação das normas trabalhistas. Portanto, a aprovação da reforma trabalhista dividiu opiniões, levantou debates e gerou muita controvérsia. Seus defensores afirmavam que a 
rigidez da legislação era contrária aos tempos modernos, argumentando que a somente a flexibilização das relações de trabalho poderia incentivar e reaquecer o mercado de trabalho, impulsionando a geração de empregos, a produtividade e a competitividade.Os que se posicionaram contrariamente asseguravam que esta flexibilização seria um grande equívoco,incapaz de melhorar o quadro de desemprego,poisofomento da economia não deve estar associado à regulamentação das relações de trabalho (CESIT, 2017).

\section{O ACONTECIMENTO: A APROVAÇÃO DA LEI 13.467/2017}

A escolha do acontecimento "aprovação da lei da reforma trabalhista" para a realização da análise de conjuntura e elaboração do presente artigodecorre de sua relevância social e econômica a nível nacional e pela repercussão de seus efeitos. Souza (2009, p. 11) afirma que"identificar os principais acontecimentos de determinado momento, ou período de tempo, é um passo fundamental para se caracterizar e analisar uma conjuntura". Neste sentido, é importante diferenciar fatos de acontecimentos, pois, diariamente ocorrem milhares de fatos em todo o mundo, porém, somente alguns deles podem ser considerados acontecimentos "aqueles que adquirem um sentido especial para um país, uma classe social, um grupo social ou uma pessoa". (SOUZA, 2009, p. 10).

Os dados referentes à tramitação do projeto de lei da reforma, apresentados a seguir estão disponíveis nos sites oficiais de ambas as casas legislativas do Congresso Nacional. Tal projeto de lei foi proposto pelo Poder Executivo, na pessoa do presidente da República e apresentado a Câmara dos Deputados no dia 23 de dezembro de 2016, por meio da Mensagem 668/2016, que submeteu o texto à deliberação do Congresso Nacional. A proposta inicial, apelidada de minirreforma, continha apenas 9 páginas, incluindo-se as 3 páginas de justificativa, assinada por Ronaldo Nogueira, Ministro do Trabalho, à época. Inicialmente previa a alteração de poucas disposições da CLT, algo em torno 13 artigos da CLT, envolvendo modificações deredação, inclusões e revogações; e uma reformulação na Lei 6.019/1974, que regulamenta o trabalho temporário, a qual impactaria em aproximadamente 10 disposições. $\mathrm{O}$ textofoi encaminhado ao Congresso Nacional em caráter de urgência e recebeu a denominação de Projeto de Lei6.787/2016 (PL 6.787/2016).

A justificativa do projetocolocaentre os principais objetivos da reforma, o de“aprimorar as relações do trabalho no Brasil, por meio da valorização da negociação coletiva entre trabalhadores e empregadores" (p.7), garantindo força de lei aos acordos e convenções coletivas em hipóteses elencadas, como, por exemplo parcelamento de férias, jornada de trabalho, intervalo intrajornada e banco de horas. O projeto também pretendia "atualizaros mecanismos de combate à informalidade da mão-de-obra no país" (p.8), mediante a regulamentação dos valores das multas administrativas previstas no artigo 47 da CLT, no caso de empregados não registrados; e ainda, em razão da omissãodos dados previstos no parágrafo único do artigo 41da CLT na carteira de trabalho dos obreiros; bem como a previsão da atualização monetária dos valores dessas multas. Seu intuito originaltambém erao de regulamentar o artigo 11 da Constituição Federal de 1988 (CF/88) "que assegura a eleição de representante dos trabalhadores na empresa, para promover-lhes o entendimento direto com os empregadores" (p. 8). Por fim,almejava a atualização da Lei 6.019/1974, "promovendo maior flexibilidade no processo de contratação de trabalhadores, ao permitir que a empresa tomadora de serviço possa contratar diretamente trabalhadores" (p. 9) (BRASIL, 2016).

O projeto foi enviado ao Congressopara deliberação em fevereiro de 2017, na volta do recesso parlamentar. Em um despacho realizado no dia 03 de deste mesmo mês, o presidente da Câmara dos Deputados, Rodrigo Maia (DEM-RJ), ordenou a constituição de uma Comissão Especial para analisar e emitir parecer sobre a matéria. Tal medidase justifica em razão do disposto no artigo 34, inciso II, do Regimento Interno da Câmara dos Deputados (RICD), que 
prevê a criação deste tipo de comissão nos casos de "preposições que versarem matéria de competência de mais de três comissões que devam pronunciar-se quanto ao mérito". No caso em análise, apresentavam competência para apreciação da matéria as Comissões de Seguridade Social e Família; de Desenvolvimento Econômico, Indústria, Comércio e Serviços; Trabalho, Administração e Serviço Público; e, ainda, de Constituição, Justiça e Cidadania, que deveria se pronunciar tanto relativamente ao mérito da matéria como também pela sua juridicidade e constitucionalidade(artigo 54, RICD).

A Comissão Especial foi constituída e instalada no dia 09 de fevereiro, tendo sido eleito como seu presidente o deputado federal Daniel Vilela (PMDB-GO) e como relator da matéria o deputado Rogério Marinho (PSDB-RN). Era composta por 36 membros titulares e o mesmo número de suplentes.Inicialmente, esta comissão seria responsável por elaborar um parecer de caráter conclusivo, o que significa que o texto, após ser votado e aprovado por ela, iria diretamente para a apreciação do Senado Federal, sem necessidade de passar pelo Plenário principal da Casa. Porém, no dia 19 de abril de 2017, após a aprovação do requerimento 6.292/2017, assinado pelos líderes dos partidos e do governo, houve a alteração no regime de tramitação do projeto, exigindo-se, então, sua apreciação pelo órgão.

Em 12 de abril de foi apresentado à comissão o parecer do relator e o texto substitutivo da proposta, contendo mais de 132 páginas. Segundo este parecer, disponível no site da Câmara dos Deputados, teriam sido apresentadas, entre os dias 13 a 22 de março, 850 emendas à proposição e realizadas pela comissão 17 audiências públicas, no período entre 16 de fevereiro a 06 de abril; 7 seminários estaduais, realizados de 20 de março a 10 de abril e outros 37 eventos diversos, entre audiências, reuniões, acompanhamentos, palestras, workshops e debates, realizados entre 07 de fevereiro a 10 de abril.Houve abertura de prazo dos dias 20 a 24 de abril para a apresentação de emendas ao substitutivo, que no total,acabou recebendo mais 457 propostas.O parecer final do relator e as emendas foram aprovadospela Comissão no dia 25 de abril e a subemenda substitutiva foi enviada, já no dia seguinte para votaçãoem turno único no Plenário. Em 26 de abril de 2017, a matéria e mais 32 emendasapresentadas à subemenda, foram discutidas no Plenário e, ao final do dia, encontrava-se aprovada na Câmara.

O passo seguinte foi a remessa do texto para deliberação no Senado Federal, realizada, no dia 28 de abril de 2017, por meio do Ofício 362/17/SGM-P. Sua tramitação se inicia em02 de maio, dia em que a matéria é lida no Plenário e projeto passa a ser denominado PL 38/2017. Por determinação da presidentedo Senado, Eunício Oliveira (PMDB-CE), a matéria foi enviada às Comissões de Assuntos Econômicos (CAE), de Assuntos Sociais (CAS) e de Constituição, Justiça e Cidadania (CCJ).O presidente da CAE, senador Tasso Jereissati (PSDB-CE) designou como relator da matéria o senador Ricardo Ferraço (PSDB-ES), que apresentou seu parecer favorável ao projeto no dia 23 de maio.A votação nacomissão aconteceu dia 06 de junho, com o placar final de 14 votos favoráveis e 11 contrários. O relatório favorável passou a constituir o parecer da CAE. Nesta fase foram apresentadas 242 emendas, todas rejeitadas.

Após a aprovação na CAE, o projeto foi enviado à CAS e sua presidente, senadora Marta Suplicy (PMSB-SP) designou, novamente, o senador Ricardo Ferraço como relator da matéria. Nesta fase foram apresentadas 226 emendas, todas rejeitadas também.A votação nesta comissão ocorreu dia 20 de junho, no entanto, o relatório foi rejeitado, por 10 votos a 9. Deste modo, conforme determina o regimento interno do Senado, ao final da votação, o senador Paulo Paim (PT-RS), apresentou um novo texto, sugerindo rejeição integral da reforma, que foi aprovado e se tornou o parecer desta comissão.A última comissão pela qual o projeto tramitou no Senadofoi a CCJ, na qual foi designado pelo seu presidente,senador Edison Lobão (PMDB-MA), como relator da matéria o senador Romero Jucá (PMDB-RR), que apresentou relatório com voto favorável no mesmo dia, 20 de junho. Nesta fase de foram recebidas 207 propostas de emendas, entre 20 a 22 de junho. A CCJ foi responsável pela realização de uma única audiência pública no 
dia 27 de junho. Por fim, o relatório favorável foi aprovado no dia 28 de junho, com 16 votos a favor, 9 contrários e uma abstenção, rejeitadas todas as emendas.

Após a discussão pelas comissões, o texto foi enviado, ainda no dia 28, para o Plenário, acompanhado dos pareceres de cada comissão. Abriu-se prazo entre os dias 30 de junho a 06 de julho para apresentação de emendas a serem discutidas no Plenário, que totalizaram 177ao final. A votação ocorreu dia 11 de julho de 2017 e o texto foi aprovado, ressalvados os destaques e as emendas de plenário. $\mathrm{O}$ texto final, com 300 páginas, foi enviado à sanção presidencial no dia 12 de junho de 2017. Na mesma ocasião, também foi remetido um oficio à Câmara dos Deputados, comunicando a aprovação do projeto sem alterações, em revisão.A sanção ocorreu no dia 13 de julho e o projeto foi transformado em norma jurídica, a Lei $13.467 / 2017$, publicada no Diário Oficial da União no dia seguinte. Porém, como a lei previa um período de vacância de 120 dias, passou a valer no ordenamento jurídico somente após transcorrido este período, que se findou no dia 11 de novembro de 2017.

Uma medida negociada entre o Congresso e o Planalto, para acelerar a aprovação da reforma, sugeriu que todas as emendas apresentadas no decorrer da tramitação do projeto no Senado fossem todas rejeitadas. O texto seria, assim, aprovado sem modificações, para que não houvesse a necessidade de retornar para discussão na Câmara, sendo posteriormente corrigido e complementado por uma medida provisória a ser editada pelo presidente da República. Esta medida foi tomada pelo presidente, com a publicação da Medida Provisória(MP) 808/2017, que permaneceu em vigência durante mais de 120 dias, entre os dias 14 de novembro de 2017 e 23 de abril de 2018, mas perdeu sua validade ao não ser discutida e aprovada pelo Congresso, de modo que, atualmente, continua valendo o texto original aprovado no Congresso, sem as complementações da MP.

É precisoevidenciar a tramitação extremamente rápida da lei, tanto na Câmara quanto no Senado. Entre o despacho inicial em 03 de fevereiro até sua aprovação na primeira Casa, em 26 de abril de 2017, foram apenas 02 meses. A tramitação no Senado, iniciada em 02 de maio e finalizada em 11 de julho de 2017, também foi de 02 meses, resultando em um total de 04 meses de discussões. Em tão curto espaço de tempo, um texto de apenas 9 páginas se transformou em documento final com mais de 300 páginas e promoveu a alteração de mais de 100 dispositivos da CLT; além de alteração significativa na Lei 6.019/1974. Ao final, a reforma ainda gerou reflexos e modificações nas Lei 8.036, de 11 de maio de 1990 e 8.212, de 24 de julho de 1991, que discorrem sobre o FGTS e Seguridade Social, respectivamente.

\section{CENÁRIO: O CONGRESSO NACIONAL}

Segundo Herbert de Souza (2009), cenário pode ser definido como o espaço ou o local onde se desenvolvem as ações da trama social e política, ou seja, é o palco onde os acontecimentos se dão. Cada um destes espaços determinados apresenta particularidades que influenciam no desenvolvimento da trama.No caso da aprovação da lei da reforma trabalhista, o palco onde se desenvolveram as discussões e a aprovação de tal medida foi no âmbito do Poder Legislativo, representado pelo Congresso Nacional. Para que se possa entender como se desenvolveu tal tramitação, é de suma importância entender como se dá a composição deste órgão.

O Poder Legislativo no Brasil, em âmbito federal, é bicameral, isto é, composto por duas casas: a Câmara dos Deputados e o Senado Federal. A primeira casa, a Câmara dos Deputados, é composta pelos representantes do povo, ou seja, por deputados federais eleitos que manifestam a vontade popular, sendo eleitosem número proporcional à população de cada Estado e do Distrito Federal, não podendo cada Estado e o DF ter menos que 8, nem mais que 70 representantes(LENZA, 2013). 
O mandato de cada deputado dura uma legislatura, isto é, 4 anos, sendo eleito pelo princípio proporcional. Neste sistema, o eleitor credita seu voto não apenas no candidato escolhido, mas também no partido ao qual ele pertence ou à coligação da qual faz parte. Deste modo, nem sempre o deputado votado será eleito, pois voto entra para o cálculo do coeficiente eleitoral, compondo a votação do partido ou coligação, resultando muitas vezes na eleição de candidatos com votação inexpressiva, pois os mais votados acabam "puxando" os demais para ocupar as cadeiras na Câmara. Tal coeficiente é obtido dividindo-se o número de votos válidos pelo de vagas a serem preenchidas.

O número total de deputados é estipulado pela Lei Complementar 78, de 30 de dezembro de 1993 e, desde o ano de sua edição, a Câmara é composta por 513 membros, cálculo elaborado conforme dados estatísticos fornecidos pelo Instituto Brasileiro de Geografia e Estatística (IBGE).Segundo informações obtidas no site da Câmara, a distribuição e representação dos deputados por Estado se dá da seguinte maneira: oque possui o maior número é São Paulo (70), seguido por Minas Gerais (53), Rio de Janeiro (46), Bahia (39), Rio Grande do Sul (31), Paraná (30) Pernambuco (25), Ceará (22), Maranhão (18), Goiás e Pará (17), Santa Catarina (16), Paraíba (12), Espírito Santo e Piauí (10), Alagoas (9) e, por fim, os Estados do Acre, Amazonas, Amapá, Mato Grosso do Sul, Mato Grosso, Rio Grande do Norte, Rondônia, Roraima, Sergipe, Tocantins e o Distrito Federal, todos com 8 deputados cada.

Já em relação à segunda casa, o Senado Federal, tem-se que este é composto por representantes dos Estados e do Distrito Federal, em número fixo de 3 para cada Estado e para o DF, totalizando 81 senadores, conforme disposto no artigo 46, da CF/88. A eleição no Senado ocorre de maneira diversa da Câmara, porque nesta casa o princípio que vige é o majoritário, isto é, são eleitos os candidatos mais votados. A duração do mandato também diverge da Câmara, pois os senadores são eleitos para um mandato de 2 legislaturas, portanto, 8 anos, todavia, a renovação se dá a cada 4 anos, na proporção de 1/3 e 2/3 das cadeiras (LENZA, 2013).

O documento "Radiografia do Novo Congresso: Legislatura 2015-2019", produzido pelo Departamento Intersindical de Assessoria Parlamentar (DIAP), apresenta interessantes informações em relação à renovação do Congresso Nacional eleito em 2014: foram renovados um total de $46,59 \%$ da Câmara e $81,48 \%$ em relação às vagas em disputa no Senado, que era de apenas 1/3, ou seja, 27 cadeiras. O documento informa ainda que um total de 387 dos 513 deputados federais concorreram à reeleição $(75,44 \%$ da composição da Câmara), e que 274 deles conseguiram lograr êxito em renovar seus mandatos $(53,41 \%)$. No Senado, dos 27 senadores que terminaram seus mandatos em 2014, apenas 10 participaram das eleições e somente 05 foram reeleitos para a próxima legislatura (18,52\%) (DIAP, 2014).

No que concerne à composição partidária do Congressono decorrerda votação da reforma trabalhista, têm-se que a Câmara estava composta de 26 partidos, com distribuição das cadeiras da seguinte forma: PMDB (64); PSDB (47); PT (58); PP (47); PSB (34); PSD (37); DEM (30); PR (39); PDT (19); PTB (18); PCdoB (11); Rede (4); PPS (9); PRB (23); PSC (10); PEN (3); PHS (7); PMB (1); Pros (5); PRP (1); PSL (2); PSOL (6); PTdoB (4); PTN (13); PV (6); Solidariedade (14).Sem considerar as ausências e os deputados que votaram contrários à orientação de seus partidos, o governo contava com o apoio de 17 partidos, que totalizavam possibilidade 358 votos favoráveis. Do mesmo modo, se posicionaram contrários à reforma 8 partidos, que representavam um total de 147 deputados. Um único partido (PHS) liberou a bancada, deixando livre a opção de voto de seus deputados, totalizando 7 votos possíveis.

Já em relação ao Senado,durante a votação da reforma trabalhista,as cadeiras estavam distribuídas entre 17 partidos, da seguinte maneira: PMDB (22); PSDB (11); PT (9); PP (7); PSB (6); PSD (5); DEM (4); PR (4); PDT (2); PTB (2); PCdoB (1); Rede (1); PTC (1); PPS (1); PRB (1); PSC (1); Podemos (1); sem partido (1). No Senado, eram 18 partidos, sendo que 11 apoiavam a aprovação da reforma, o que simbolizava 60 votos favoráveis (novamente, sem considerar ausências e votos contrários), e 7 partidos com orientação contrária à aprovação, 
somando 20 votos possíveis. Apenas um senador não possuía orientação de voto, por não estar vinculado a nenhum partido.

Como se vê, o governo contava com uma probabilidade relativamente alta de aprovação da reforma, em razão da menor expressividade numérica dos partidos de oposição. $\mathrm{O}$ contexto efetivo da aprovação, com os números finais da votação serão apresentados e discutidos no tópico referente aos atores.

\section{ASPECTOS ANTERIORES}

Diversos foram os aspectos anteriores que podem ter influenciado direta ou indiretamentena medida tomada pelo Governo que culminou na aprovação da lei objeto desta análise.As considerações apresentadas neste tópico são embasadas, em maior parte, em um levantamento temporalapresentado pelo jurista, Jorge Luiz Souto Maior, na publicação "A quem interessa essa reforma trabalhista?", vinculada em seu blog, no dia 01 de maio de 2017, no qual o autor apresenta um histórico da reforma, discorrendo sobre os principais acontecimentos que impactaram na propositura de tal medida.

Uma informação interessante abordada no documento "Dossiê da Reforma Trabalhista", elaborado pelo Centro de Estudos Sindicais e de Economia do Trabalho (CESIT), é que grande parte das premissas que embasaram o texto da reforma, desde a versão original, apresentada pelo Poder Executivo, quanto do texto substitutivo apresentado pelo deputado Rogério Marinho (PSDB/RN), bem como as que estão presentes na redação final da lei aprovada pelo Congresso Nacional, são encontradas em diversas formulações de organizações patronais. O dossiê cita, por exemplo, os textos de autoria da Confederação Nacional da Indústria (CNI) editados nos últimos anos, que propagavam o mesmo ideal da reforma, quais sejam "101 Propostas para Modernização Trabalhista", de 2012, bem como "Agenda Legislativa da Indústria", de 2014; e, por fim, "Caminhos da Modernização Trabalhista", de 2016. Eram em mesmo sentido as formulações propostas pela Confederação da Agricultura e Pecuária (CNA)nos documentos: "Proposta da Bancada de Empregadores", publicado no ano de 2016; "Balanço 2016"e "Perspectivas 2017". (CESIT, 2017).

A tendência de aprovação da reforma trabalhista se confirmou muito antes que as primeiras discussões envolvendo o tema efetivamente ocorressem a um nível mais formal. A eleição de um Congresso pulverizado partidariamente, liberal do ponto de vista econômico e conservador do ponto de vista social, conforme os dados apresentados na publicação "Radiografia do Novo Congresso - Legislatura 2015-2019", publicada em dezembro de 2014, de autoria do DIAP, tornaram muito mais fácil o processo.O conservadorismo do ponto de vista social possui três dimensões: "a redução da bancada sindical, no aumento da bancada empresarial e na resistência aos programas sociais, como as políticas afirmativas de cotas e o programa Bolsa Família.” (DIAP, 2014, p. 15).

Conforme demonstra o documento demonstram que houve uma redução da bancada sindical de 83 membros para apenas 59, sendo 50 deputados e 9 senadores, ao mesmo tempo em que se conservou uma maior expressividade da bancada empresarial, com 250 parlamentares atuantes em defesa do setor produtivo. Em relação à afirmação de que o Congresso é mais liberal do ponto de vista econômico, o relatório revela uma redução do número de representantes de partidos de esquerda, centro-esquerda e centro, "que reconheciam e defendiam um papel proativo do Estado na economia" e, consequentemente, um aumento no número de representantes de partidos de direita, com ideologia mais liberal, que "entendem que o mercado é perfeito e que o Estado não deve atuar na atividade econômica, nem como regulador nem como produtor e fornecedor de bens ou serviços." (DIAP, 2014, p. 14-15).

Outroaspecto anteriorrelacionado com a possibilidade de abertura das discussão e consequente aprovação da reforma trabalhista é o impeachment da presidente Dilma Rousseff, 
ocorrido no ano de 2016. Logo após a abertura do processo, em 02 de dezembro de 2015, constata-se que diversas entidades empresariais começaram a se posicionar favoravelmente ao afastamento definitivo da presidente. Pode-se citar como exemplo a Federação das Indústrias de São Paulo (Fiesp) e o Centro das Indústrias do Estado de São Paulo (CIESP) que se manifestaram, expressamente, a favor do impeachment já em dezembro de 2015. O diretor de ambas as entidades, Paulo Skaf, anunciou durante uma entrevista coletiva realizada dia 13 de dezembro, o posicionamento favorável das instituições em relação ao processo de impeachment. Outras entidades como a Confederação da Agricultura e Pecuária (CNA), a Confederação Nacional da Indústria (CNI) e a Confederação Nacional do Transporte (CNT), manifestaram seu apoio ao impeachment, um pouco mais tarde, em abril de 2016. (SOUTO MAIOR, 2017b).

Inclusive, afala de alguns dos presidentes dessas entidades,possuíam alegaçõesmuito próximas,culpabilizando o governo Dilma pela instabilidade da economia e pelo crescimento do desemprego. Eles declaravamque medidas erradas empregadas pelo governogeraram instabilidade na economia e "provocaram o crescimento do desemprego (...) o fechamento de 100 mil estabelecimentos comerciais em todo país, gerando 10 milhões de desempregados", ocasionando "a perdade credibilidade junto à população e à comunidade financeira internacional". Para eles, portanto, o impeachment, a mudança de governo,seriaa única saída para se retomar a confiança no país e recuperar a economia (SOUTO MAIOR, 2017b).

Um pouco antes do processo de impeachment se desenrolar na Câmara dos Deputados, o PMDB, que ainda compunha o governo, apresenta, em 29 de outubro de 2015, seu programa de medidas para alavancar a economia e tornar viável o desenvolvimento do país, denominado "Uma Ponte para o Futuro", (SOUTO MAIOR, 2017b). Ainda que tal programa, formulado pela Fundação Ulysses Guimarães, não contivesse um verdadeiro projeto de reforma trabalhista, apresentava uma série de iniciativas/propostas de reformas estruturais, envolvendo, entre outros pontos, a questão fiscal e previdenciária, além de "na área trabalhista, permitir que as convenções coletivas prevaleçam sobre as normas legais, salvo quanto aos direitos básicos" (FUNDAÇÃO, 2015).

No entanto, mesmo após a abertura do processo de impeachment, não se vislumbrou nenhuma atitude dopresidente (agora interino) no sentido de promover qualquer reforma trabalhista, colocando todos os seus esforços na reforma da previdência, que era sua prioridade até então. Inclusive, o Ministro do Trabalho, Ronaldo Nogueira, afirmava em maio de 2016 que primeiro ouviria os trabalhadores e que antes de tomar qualquer medida, iria buscar construir uma base consensual com os sindicatos (SOUTO MAIOR, 2017b).

A publicação aponta, ainda, como antecedente à reforma, uma possível pressão que o setor empresário passou a exercer sobre o governo pouco tempo depois, quandono dia 08 de julho de 2016, 150 empresários, de diversos setores, teriam ido até o Planalto encontrar com o presidente interino, com o objetivo de“expressar o seu apoio ao governo e aproveitar para lembrá-lo do compromisso assumido com relação às reformas estruturais na Previdência e na legislação do trabalho" (SOUTO MAIOR, 2017b). A partir deste momento, o discurso do Ministro do Trabalho muda de tom e ele passa defender a alteração na legislação trabalhista. Acompanhando o discurso dele, o Ministro da Casa Civil também passa a afirmar a necessidade da reforma.Para Souto Maior (2017b), a mídia também teria desempenhado um importante papel no desenrolar dos acontecimentos, atuando de modo apressionar o governo a promovertal medida, como por exemplo, quando no dia 20 de julho de 2016, o jornal Folha de São Paulo noticiou que "o governo iria enviar ao Congresso Nacional, até o final do ano, três propostas na área trabalhista": uma atualização da CLT, a regulamentação da terceirização e a transformação do Programa de Proteção ao Emprego (PPE) em algo permanente. (SOUTO MAIOR, 2017b).

Entre os aspectos anteriores da reforma, o jurista discorre sobre a atuação do Supremo Tribunal Federal (STF), que passou a ajustar cuidadosamente suas decisões à tal projeto, antes mesmo queele fosse formalmente discutido, proferindo decisões que faziam, inclusive, uma 
apologia ao negociado sobre o legislado. Ainda em 2016, consoante o levantamento feito por ele, o STF" provavelmente pela primeira vez em toda a sua história, designou uma pauta composta integralmente de processos que diziam respeito a questões trabalhistas", sendo que todas as discussões eram relacionadas ao tema da flexibilização, buscando-se "promover uma autêntica reforma jurisprudencial trabalhista, passando por cima dos entendimentos, nas mesmas matérias, já expressos pelo Tribunal Superior do Trabalho" (SOUTO MAIOR, 2017b).

Conforme Souto Maior (2017b), em razão desse comportamento do STF, o presidente Michel Temer teria visto uma oportunidade dedeixar a pauta da polêmica reforma para o segundo semestre de 2017. A fala do Ministro do Trabalho, Ronaldo Nogueira, em setembro de 2016, reproduzida na publicação,seguia no mesmo sentido de que a questão da reforma era complexa e que todos os setores envolvidos deveriam ser ouvidos; "que antes de discutir mudanças na lei trabalhista, o governo iria focar na recuperação da economia" (SOUTO MAIOR, 2017b). Com isto ficava evidenciada a ausência de uma proposta concreta de reforma trabalhista por parte do governo. Como se vê, o governo tentou adiar de todas as maneiras a discussão da reforma, mudando de discurso diversas vezes quanto à sua real necessidade.

Mas a pressão do setor empresarial continuou e o governo não teve outra saída a não ser apresentar um projeto de lei para a tal reforma. No dia 22 de dezembro de 2016, no Palácio do Planalto, com as presenças dos Ministros Gilmar Mendes e Ives Gandra da Silva Martins Filho, Michel Temer e Ronaldo Nogueira se unem para anunciar a apresentação oficial do projeto, e informar que o governo iria liberar, a partir de $1^{\circ}$ de fevereiro de 2017, o FGTS das contas inativas dos trabalhadores. Com tal medida, o governo conseguiu, acalmar os ânimos de empregados e empregadores e "alterar a pauta da grande mídia, colocando a notícia da reforma trabalhista nas primeiras páginas" (SOUTO MAIOR, 2017b).

\section{FATORES EXÓGENOS}

Os fatores exógenos podem ser entendidos como sendo fatores externos ao acontecimento, mas que possuem influência nos atores, no cenário e no desenrolar da trama social. Os defensores da reforma argumentavam que a crise econômica experimentada pelo país nos últimos anos era a grande responsável pela necessidade de tal reforma. Conforme notícia veiculada pelo portal G1 em março de 2017, o Produto Interno Bruto Brasileiro (PIB) experimentou forte queda por dois anos consecutivos, entre 2015 e 2016, confirmando a pior recessão da história do país, segundo dados divulgados pelo Instituto Brasileiro de Geografia e Estatística (IBGE), em 07 de março de 2017. A retração total do biênio foi de 7,2\%, sendo que uma sequência de dois anos seguidos de baixa só foi verificada no Brasil nos anos de 1930 e 1931 quando os recuos foram de $2,1 \%$ e 3,3\%, respectivamente. Pela primeira vez desde 1996, todos os setores da economia registraram taxas negativas: a crise foi generalizada e os três setores que entram no cálculo do PIB recuaram no ano de 2016(a agropecuária -6,6\%; a indústria -3,8\% e os serviços $-2,7 \%)$.(G1, 2017).

Outro fator exógeno que teve forte influência na aprovação da reforma trabalhista, ainda no cenário econômico, foram as altas taxas de desemprego, que atingiu seu auge no primeiro trimestre de 2017,com mais de 14,2 milhões de brasileiros desempregados, de acordo com a Pesquisa Nacional por Amostra de Domicílios (Pnad) contínua, divulgada em 28 de abril de 2017, pelo IBGE. O número de desempregados no período compreendido janeiro e março de 2017 atingiu 13,7\%, recorde da pesquisa iniciada em 2012. A promessa principal da reforma era a de combater o desemprego mediante a flexibilização dos direitos, que oportunizaria o reaquecimento do mercado.

Como se vê, a crise realmente existiu e o desemprego atingiu níveis altíssimos, principalmente se comparado aos anos anteriores, como, por exemplo, quando em 2014 se atingiu o menor índice da história $(4,8 \%)$. Mas tal crise tem como causa outros fatores, como a má gestão 
de gastos e subsídios públicos que geraram um aumento da dívida pública e a instabilidade política experimentada pelo país; e outros de caráter internacional, inclusive, como desaceleração da economia chinesa e queda dos preços das commodities (que são matérias-primas e produtos agrícolas), que no período anterior, entre 1990 e 2012, apenas crescia. A crise econômica dava seus primeiros sinais ainda em 2013, mas só atingiu seu ápice entre os anos de 2016 e 2017 . No entanto, pelos dados apresentados, os menores índices de desemprego na história do paísforam atingidos durante a vigência do texto antigo da CLT, de modo é possível afirmar que este fator não está relacionado diretamente à regulamentação das relações de trabalho e sim ao desempenho da economia. Portanto, reduzir ou flexibilizar direitos não trará benefício algum para a redução da taxa de desemprego no país, muito pelo contrário, pois mesmo após a aprovação da reforma as taxas no país mantiveram seus altos índices.

Conforme matéria vinculada pelo site Nexo Jornal, em 02 de maio de 2017, também influencioupositivamente à aprovação da reforma a ajuda que o governo encontrou dentro do Congresso para promover tal medida. A vaga depresidente do Senado estava sendo ocupada pelo senador Eunício Oliveira (PMDB-CE), que defendeu a reforma trabalhista e teve muito poder de influência no trâmite do projeto de lei dentro da Casa; afinal, "caso a cadeira ainda estivesse ocupada por Renan Calheiros (PMDB-AL), o governo teria mais dificuldade para encaminhar o texto", visto que Renan deu diversas declarações se posicionando contrariamente à reforma (NEXO JORNAL, 2017b).

A ampla base de apoio que o governo tinha tanto na Câmara quanto no Senado pesou favoravelmente à reforma. Ainda assim, segundo a publicação, o Presidente Michel Temer teria usado "a distribuição de verbas e cargos para tentar convencer deputados a votar a reforma trabalhista e ameaça retaliar os aliados que votaram contra a medida" (NEXO JORNAL, 2017a). Em outra reportagem, publicada em 11 de abril de 2017, o site traz a informação de que uma negociação entre o governo e os parlamentares teria garantido a liberação de $\mathrm{R} \$ 1,8$ bilhão em emendas parlamentares; recursos que estavam previstos apenas para o final de 2017, mas que foram antecipados e pagos em abril, para garantir a aprovação da lei. (NEXO JORNAL, 2017b).

Um último fator que pode ser encarado como um facilitador para a aprovação doprojetoé o fato de que, como ela não visava alterar a $\mathrm{CF} / 88$, sua aprovação dependia do da maioria simples do Congresso, ou seja, por se tratar de um projeto de lei simples, bastaria o apoio de metade mais um dos deputados e senadores presentes durante a votação, em turno único. Com um resultado mais fácil de ser alcançado do que as propostas de emenda à Constituição, como a da reforma da Previdência, que precisam do voto de pelo menos três quintos dos congressistas em dois turnos, a aprovação da Lei 13.467/2017 foi relativamente fácil de ser conquistada(NEXO JORNAL, 2017b).

No que diz respeito aos aspectos desfavoráveis à aprovação da reforma trabalhista está sua amplitude e impopularidade, visto que alterou diversos artigos da CLT e de outras cinco leis, sendo que a maior parte das propostas de alteração foram incluídas duas semanas antes da votação, sem muito tempo para debate. O texto foi e é criticado por todas as centrais sindicais, além de contar com grande reprovação popular, conforme apontado em pesquisa do Instituto Datafolha, divulgada em 02 de maio de 2017. O levantamento efetuado entre os dias 26 e 27 de abril do mesmo ano, no qual foram realizadas 2.781 entrevistas em 172 municípios brasileiros, constatou-se a maioria dos brasileiros estava pessimista com relação à aprovação de tal reforma, pois para a maior parcela dos entrevistados, ela traria mais benefícios para os empresários do que para os trabalhadores (64\%) e acarretará em menos direitos para os trabalhadores (51\%) (DATAFOLHA, 2017).Outra pesquisa realizada entre os dias 27 e 31 de outubro, pela CUTVOX Populi, e publicada em 02 de novembro de 2017, apontava a reprovação de aproximadamente $81 \%$ dos brasileiros às novas regras trabalhistas. A publicação afirma que o maior índice de rejeição às mudanças foi encontrado no Sudeste do país (89\%), seguido pelo Nordeste (81\%), Centro-Oeste/Norte (78\%); e Sul (60\%).Para 67\% dos entrevistados, a nova Lei 
Trabalhista só é boa para os patrões, resultado este bastante assemelhado ao encontrado pela pesquisa da Datafolha (CUT, 2017).

Também pesou desfavoravelmente à aprovação da reforma a proximidade com da discussão com as eleições de 2018, na qual sepermitirá, além da renovação de toda a Câmara, a renovação de dois terços do Senado, portanto, dos 81 senadores, 54 estão no fim de seus mandatos, e grande parte deles será candidato a reeleição ou a outros cargos eletivos ou tentarão influir no pleito de outubro de 2018 em seus Estados. A depender de sua base, o posicionamento na reforma trabalhista poderia resultar em desgaste eleitoral desnecessário e perigoso e lógica semelhante se aplica à Câmara dos Deputados. Ainda que o governo Temer contasse com uma base extensa, tanto na Câmara quanto no Senado, se sentiu ameaçado, pois a oposição tentava a todo momento atrair aliados para atrasar ou engavetar o projeto (NEXO JORNAL, 2017b).

Por fim, um último fator a ser elencado era a impopularidade do presidente Michel Temer, que registrou no período taxas declinantes de popularidade (algumas pesquisas chegavam a apontar uma aprovação que variava em torno de apenas 2\% (IPSOS - 25/07/2017), a 7\% dos entrevistados (Datafolha - 24/06/2017)). Ainda que o presidente seja habilidoso articulador político e contasse com o apoio da maioria do Congresso e do empresariado, estes altos índices de impopularidade poderiam ter atrapalhado a aprovação do projeto, pois os parlamentares poderiam sopesar os ônus e bônus de estar alinhado às medidas de um governo tão impopular (NEXO JORNAL, 2017b).

Entre pontos positivos e negativos, fato é que tal projeto de lei foi aprovado sem maiores dificuldades pelo governo, diferentemente do que se verifica no caso da reforma da previdência, que ainda não conseguiu nem mesmo tramitar entre as casas do Congresso, em razão divisãoda base aliada do governo em ralação à matéria, pelo temor de suas repercussões negativas e de que, aofim aos debates o resultado seja contrário aos interesses do governo.

\section{ATORES}

Segundo Herbert de Souza (2009, p. 12) "ator é alguém que representa, que encarna um papel dentro de um enredo, de uma trama de relações". O ator pode ser um indivíduo, uma classe, uma categoria ou um grupo social, bem como instituições, sindicatos, partidos políticos, jornais, rádios, emissoras de televisão, igrejas, etc. Levando em consideração de que o cenário onde se deu o debate e a aprovação da reforma trabalhista foi o Congresso Nacional, cumpre verificar quais foram os atores que participaram de tal processo, dentro deste espaço.

A aprovação pela Câmara dos Deputados do texto base da reforma trabalhista, ocorreu no dia 26 de abril de 2017, durante a sessão extraordinária $n^{\circ}$ 94, da Terceira Sessão Legislativa Ordinária, da 55 ${ }^{\mathrm{a}}$ Legislatura (2015-2019). Haviam 474 deputados presentes na sessão, o que representa um total de $92,40 \%$. Foram 296 votos a favor da aprovação da reforma trabalhista, 62,45\% dos presentes e 177 contrários, (37,55\%), além de 38 ausências, abstenções e obstruções. No Senado, estavam presentes na votação 78 parlamentares, uma marca expressiva de 96,3\% do total, sendo que 50 votaram a favor $(64,10 \%)$, 26 votaram contra $(33,3 \%)$, houve 1 abstenção. Nos termos do artigo 51 do Regimento Interno do Senado Federal (RISF), o presidente não vota.

De acordo com um levantamento exclusivo realizado pelo site "The Intercept", e divulgado no dia26 de abril de 2017, "lobistas de associações empresariais são os verdadeiros autores de uma em cada três propostas de mudanças apresentadas por parlamentares na discussão da Reforma".A matéria traz ainda um outro dado alarmante: apósanalisar as 850 emendas apresentadas durante a fase de discussões pela Comissão Especial da Câmara, por um total de 82 parlamentares, constatou-se que 292 delas (34\%) teriam sido redigidas integralmente em computadores de entidades de representantes do setor empresarial, quais sejam: a Confederação Nacional da Indústria (CNI); a Confederação Nacional das Instituições Financeiras (CNF), a Associação Nacional do Transporte de Cargas e Logística (NTC\&Logística) e a Confederação 
Nacional dos Transportes (CNT). Para chegar a tal conclusão, teriam sido examinadas todas as emendas e encontrados, dentro dos arquivos PDF com o conteúdo da emenda, metadadosque indicam quem seria o autor original do arquivo, mostrando, inclusive a identificação do computador aonde o texto teria sido redigido.Por fim, o site ressalta que, do total de emendas vinculadas à lobistas (292), foram integralmente ou parcialmente aprovadas com o relatório final da Comissão, um total de 153 emendas (52\%).

Um outro estudo feito pelo site Esquerda Diário, e publicado em 26 de maio de 2017, apresenta mais um dado de extrema relevância. De acordo com a publicação,dentre os 296 deputados que votaram a favor da reforma trabalhista, 163 seriam empresários, sendo que 13 deles seriam donos construtoras, 17 de incorporadoras de empreendimentos imobiliários e 47 possuiriam comércios varejistas e atacadistas. Vários deles seriam donos de mais de 10 empresas e, ainda, que alguns seriam há anos representantes de entidades empresariais.A matéria afirma ainda que a maioria dos deputados que votou a favor da reforma trabalhista votou também a favor da lei da terceirização irrestrita, e que diversos deles acumulam processos trabalhistas por conta de irregularidades em suas empresas, inclusive os relatores de ambas as propostas. O site cita como exemplo o caso do Senador Laércio Oliveira (SD-SE), relator do projeto da terceirização irrestrita, que seria dono de duas empresas de terceirização entre elas, a Franca - Serviços de Vigilância e Segurança Patrimonial - que acumula dezenas de ações trabalhistas.

Conforme notícia veiculada pelo site UOL, em 26 de abril de 2017, o relator da reforma trabalhista na Câmara, Rogério Marinho (PSDB-RN), estaria sendo investigado pelo STF por suspeita de envolvimento com uma empresa terceirizada que teria coagido funcionários demitidos a renunciarem verbas rescisórias e devolverem a multa do fundo de garantia (Inquérito 3386-RN). Segundo divulgado no site, a investigaçãodo Ministério Público do Trabalho (MPT) apontava que a companhia teria, mediante fraude, se apropriado ilegalmente de $\mathrm{R} \$ 338$ mil devidos a mais de 150 trabalhadores. A notícia afirma ainda que o inquérito aponta indícios de que o deputado federal mantém sociedade com Francisco das Chagas de Souza Ribeiro, responsável pela gestão da Preservice Recursos Humanos, "tradicional fornecedora de mão de obra terceirizada - porteiros, faxineiros e cozinheiros - para o poder público em Natal, capital do Estado de origem do relator" (UOL ECONOMIA, 2017).

Já no Senado, dos 50 senadores que votaram a favor da reforma trabalhista, 37 teriam participação societária em corporações, ações ou possuiriam alguma empresa ou fazenda em seu nome, o que representa $74 \%$ dos que votaram a favor da reforma. As informações são do site Congresso em Foco, que realizou um levantamento exclusivo junto aos registros de candidatura dos senadores junto à Justiça Eleitoral, referente à declaração de bens realizada para as eleições dos anos de 2010 e 2014. O site apresenta diversos dados para corroborar com tais afirmações, como por exemplo, o patrimônio declarado de três dos senadores mais ricos da legislatura 20152018, Ronaldo Caiado (DEM-GO), Tasso Jereissati (PSDB-CE) e Wilder Morais (PP-GO), que detém um patrimônio declarado de centenas de milhões de reais. Ainda, conforme apontado pela reportagem, "duas das mais numerosas bancadas do Senado, PSDB e PMDB são os partidos com mais senadores empresários ou acionistas de empresas ou corporações congêneres", sendo 9 peemedebistas e 7 tucanos (CONGRESSO EM FOCO, 2017).

Portanto, este é um breve perfil dos atores que participaram do acontecimento aprovação da Reforma Trabalhista. Deste modo, é fácil verificar, ainda que breve este levantamento, os interesses por trás da rápida tramitação e aprovação da lei e em defesa dos interesses de quais setores da sociedade os parlamentares teriam atuado.

\section{A CORRELAÇÃO DE FORÇAS}

Ao realizar uma análise de conjuntura, podemos encontrar diversos atores que participam do acontecimento investigado. Souza (2009, p. 13) afirma que "as classes sociais, os 
grupos, os diferentes atores sociais estão em relação um com os outros". Ainda segundo o autor, "essas relações podem ser de confronto, de coexistência, de cooperação e estarão sempre revelando uma relação de força, de domínio, igualdade ou subordinação". Em uma análise de conjuntura compreender as correlações de forças existentes em determinado acontecimento significa encontrar quais "os recursos de poder que os atorespodem mobilizar na conjuntura, para tornar efetiva sua estratégia política" (QUEIROZ, 2015, p. 26). Tais recursos podem ser reais ou potenciais e podem ou não serem usados para inibir a ação dos adversários. Entre outros indicadores da força de um determinado grupo ou segmento político e socialtem-se a quantidade e qualidade dos atores que aglutinam; o espaço ou importância destes na estrutura social; a forma de consciência e unidade ideológica em relação ao interesse em disputa; o preparo estratégico e a capacidade para envolver-se na luta política e social; as alianças e estratégia de longo prazo; bem como os recursos políticos, econômicos, tecnológicos, jurídicos disponíveis. (QUEIROZ, 2015).

Pouco se ouviu falar da presença ou pressão de grupos sociais, sindicatos de trabalhadores ou mesmo da própria população, que não conseguiu exercer qualquer resistência ou oposição significativa na aprovação de tais medidas dentro do espaço de discussão e aprovação da reforma, o Congresso Nacional. Greves gerais e manifestações de expressão ocorreram em todo o país, contra a aprovação do projeto de lei, como as que ocorreram dia 28 de abril e de 30 de junho de 2017. No entanto, diante de forte repressão estatal, com a aprovação do Protocolo Tático Integrado de Manifestações, inclusive com o uso de força policial e das forças armadas, prisões e multas altíssimas para os sindicatos que descumprissem as ordens de não manifestação, não se conseguiu levar adiante tais reivindicações, nem que elas tivessem a força e o alcance das manifestações de 2015-2016 (CARTA CAPITAL, 2017a).

Conforme os dados apresentados no tópico referente aos atores da reforma, verifica-se que o governo contava com ampla margem para a aprovação da reforma, em razão da composição do Congresso Nacional, com um perfil claramente mais liberal e a presença de uma bancada muito maior atuando em defesa dos interesses do capital do que a que defende os interesses sociais e dos trabalhadores. $\mathrm{O}$ que se verificou no caso da reforma trabalhista foi o grande peso do setor empresarial e econômico do país, que além de ter estes representantes diretos no Congresso, possui forte poder de influência em razão dopoderio que o capital os propicia. A crise política e economia, bem como os escândalos de corrupção denunciados pela Operação Lava Jato, causou um enfraquecimento da oposição e desmobilizou qualquer tentativa de frear a reforma.

Deste modo pode-se afirmar que no caso da tramitação e aprovação da lei da reforma trabalhista a correlação de forças existente entre os atores era de domínio, desfavorável em relação aos trabalhadores, ou seja, apesar de algumas reações contrárias de opositores no Congresso, os defensores e protagonistas da reforma saíram vitoriosos. Portanto, a tendência inicial de aprovação do projeto foi confirmada ao fim de sua tramitação.

\section{CONCLUSÃO}

Por todo o exposto no decorrer do presente trabalho, com fundamentação nos dados colhidos na pesquisa, o que se verifica é que a reforma trabalhista promovida em 2017, atendeu em grande parte a interesses dos empresários, que inclusive compõem grande parte dos membros do Congresso Nacional, fragilizando-se juridicamente a classe trabalhadora, afastando a atuação do Estado das relações de trabalho, aumentando o poder dos detentores do capital. Portanto, não se tratou de uma verdadeira modernização das leis ou de uma simples reforma, mas sim de uma profunda alteração na regulação dasrelações de trabalho no Brasil, todas no mesmo sentido de adequar a legislação trabalhista aos ditames do capital internacional, nos moldes do que já vem ocorrendo em todo o mundo a partir da década de 1980. 
A rápida tramitação da do projeto de lei não permitiu um verdadeiro diálogo com todos os setores afetados pelas modificações ocasionadas; não permitiu, na verdade, nem mesmo uma correta e adequada redação da lei, que contém diversas inconstitucionalidades, incongruências e não se preocupou em corrigir dispositivos que estavam realmente em desuso na CLT, focando única e exclusivamente em flexibilizar e retirar direitos. Essa rapidez talvez se justifique em razão da polêmica das alterações, que não sobreviveria a um debate verdadeiramente democrático.

Muitos direitos adquiridos após anos de lutas dos trabalhadores, dos sindicatos e da população como um todo, bem como através da atuação de órgãos como o Ministério Público do Trabalho e da Justiça do Trabalho, foram retirados rapidamente e com muita facilidade pela lei. Seus reflexos negativos ainda levarão um certo tempo para serem sentidos pela população, porém os primeiros dados dos institutos de pesquisa revelam seus efeitos nefastos. Diferentemente do que afirmavam os defensores da reforma, ela não gerou mais empregos, muito pelo contrário, foram diversas dispensas em massa nos últimos meses, e, ainda que o desemprego tenha caído por um momento, ele voltou a subir pouco tempo depois, mantendo as taxas experimentadas antes da reforma. Aumentaram também as ofertas de emprego em condições mais precarizadas, com salário inferior, que junto ao cenário econômico do país, que sofre para se recuperar, gera mais insegurança e fragilidade para a classe trabalhadora no país.

Espera-se, por todo o exposto, ter contribuído com a divulgação das informações, de modo a permitir uma maior clareza sobre o assunto para os próximos debates envolvendo a aprovação de tal reforma. É necessário encontrar meios de se combater esta ofensiva do capital sobre as relações do trabalho no país, que ainda carrega a triste herança de anos de exploração, escravidão e forte desigualdade social. Relembrando que a consciência e a clareza dos acontecimentos, das regras do jogo e da correlação de forças dos atores, são alguns dos principais recursos de poder disponíveis para os atores sociais e que permitem traçar estratégias de enfrentamento e combate a tal desmonte dos direitos sociais do trabalho no Brasil.

\section{REFERÊNCIAS BIBLIOGRÁFICAS}

AGÊNCIA DE NOTÍCIAS IBGE. Editorial de Estatísticas Sociais.PNAD Contínua: taxa de desocupação vai a 13,7\% no trimestre encerrado em março de 2017. Disponível em:https://agenciadenoticias.ibge.gov.br/agencia-noticias/2013-agencia-denoticias/releases/9401-pnad-continua-taxa-de-desocupacao-vai-a-13-7-no-trimestre-encerradoem-marco-de-2017.html. Acesso em: 12 maio 2018.

ALVES, Eustáquio Diniz. (2008).Análise de Conjuntura: teoria e método. Disponível em:www.ie.ufrj.br/aparte/pdfs/analiseconjuntura_teoriametodo_01jul08.pdf. Acesso em: 05 maio 2018.

ALVES, Giovanni. Dimensões da Reestruturação Produtiva: ensaios de sociologia do trabalho. 2. ed. Londrina: Práxis; Bauru: Canal 6, 2007.

.Trabalho e mundialização do capital: a nova degradação do Trabalho na era da globalização. 2. ed. Londrina: Práxis, 1999.

ANTUNES, Ricardo. Adeus ao trabalho?Ensaios sobre as metamorfoses e a centralidade do mundo do trabalho.11. ed. São Paulo: Cortez; Campinas: Editora da Universidade de Campinas, 2006. 
.Os sentidos do trabalho: ensaios sobre a afirmação e a negação do trabalho. 2. ed. São Paulo: Boitempo, 2009.

BRASIL. (2016). Câmara dos Deputados. Projeto de Lei $\mathbf{n}^{\mathbf{0}} \mathbf{6 . 7 8 7 / 2 0 1 6}$. Altera o Decreto-Lei ${ }^{\mathbf{o}}$ 5.452, de $1^{\circ}$ de maio de 1943 - Consolidação das Leis do Trabalho, e a Lei $n^{\circ} 6.019$, de 3 de janeiro de 1974. Disponível em:

http://www.camara.gov.br/proposicoesWeb/fichadetramitacao?idProposicao=2122076. Acesso em: 22 abr. 2018.

. (1943). “Consolidação das Leis do Trabalho”. Decreto-Lei n 5.442, de 01 de maio de 1943. Diário Oficial da União, Poder Executivo, Rio de Janeiro, 09 ago. 1943. Disponível em: http://www.planalto.gov.br/ccivil_03/Decreto-Lei/Del5452compilado.htm. Acesso em: 10 maio 2018.

. (1988). “Constituição da República Federativa do Brasil”: promulgada em 5 de outubro de 1988. Diário Oficial da União, Brasília, 05 out. 1988. Disponível em: http://www.planalto.gov.br/ccivil_03/constituicao/constituicao.htm. Acesso em: 18 maio 2018.

. (2017a).Planalto. Lei 13.467/2017. Altera a Consolidação das Leis do Trabalho (CLT), aprovada pelo Decreto-Lei $\mathrm{n}^{\circ} 5.452$, de $1^{\circ}$ de maio de 1943, e as Leis $\mathrm{n}^{\circ} \mathrm{s} 6.019$, de 3 de janeiro de $1974,8.036$, de 11 de maio de 1990, e 8.212, de 24 de julho de 1991, a fim de adequar a legislação às novas relações de trabalho. Disponível em: http://www.planalto.gov.br/CCIVIL_03/_Ato2015-2018/2015/Lei/L13167.htm. Acesso em 24 abr. 2018.

(2017b).Senado Federal. Projeto de Lei da Câmara no 38/2017. Altera a Consolidação das Leis do Trabalho (CLT), aprovada pelo Decreto-Lei $n^{\circ} 5.452$, de $1^{\circ}$ de maio de 1943, e as Leis n's 6.019, de 3 de janeiro de 1974, 8.036, de 11 de maio de 1990, e 8.212, de 24 de julho de 1991, a fim de adequar a legislação às novas relações de trabalho. Disponível em:https://www25.senado.leg.br/web/atividade/materias/-/materia/129049. Acesso em: 27 abr. 2018.

CARTA CAPITAL. (2017a).Perdeu o dia de caos em Brasília? Entenda o novo episódio da crise.Política. Disponível em:https://www.cartacapital.com.br/politica/perdeu-o-dia-de-caos-embrasilia-entenda-o-novo-episodio-da-crise. Acesso em: 26 maio 2018.

(2017b).Contra reformas de Temer, greve mira transportes e rodovias. Política. Disponível em:https://www.cartacapital.com.br/politica/contra-reformas-de-temer-greve-miratransportes-e-rodovias. Acesso em: 19 maio 2018.

CESIT - Centro de Estudos Sindicais e de Economia do Trabalho. (2017), Contribuição Crítica à Reforma Trabalhista. GT Reforma Trabalhista CESIT/IE/UNICAMP. Disponível em: http://www.cesit.net.br/wp-content/uploads/2017/06/Dossie-14set2017.pdf. Acesso em: 10 maio 2018.

CONGRESSO EM FOCO. (2017).Senadores-empresários foram maioria absoluta dos votos a favor da reforma trabalhista; veja a lista. Disponível em: http://congressoemfoco.uol.com.br/noticias/senadores-empresarios-foram-maioria-absoluta-dosvotos-a-favor-da-reforma-trabalhista-veja-a-lista/. Acesso em:17 maio 2018. 
CUT. (2017).CUT/Vox confirma: $81 \%$ dos trabalhadores rejeitam Reforma Trabalhista. Disponível em:https://cut.org.br/noticias/cut-vox-confirma-81-dos-trabalhadores-rejeitamreforma-trabalhista-bd73/. Acesso em: 18 maio 2018.

DIAP - Departamento Intersindical de Assessoria Parlamentar. Radiografia do Novo Congresso: Legislatura 2015-2019. Departamento Intersindical de Assessoria Parlamentar. Brasília, DIAP, 2014.

ESQUERDA DIÁRIO. (2017).De cada 10 deputados favoráveis à reforma trabalhista, 6 são empresários. Disponível em: http://www.esquerdadiario.com.br/De-cada-10-deputadosfavoraveis-a-reforma-trabalhista-6-sao-empresarios. Acesso em:23 maio 2018.

FUNDAÇÃO ULYSSES GUIMARÃES. (2015).Uma ponte para o futuro: Uma proposta para tirar o Brasil da Crise. Brasília. Disponível em: http://www.ponteparaofuturo.org.br/docs/RELEASE-TEMER_A4-28.10.15-Online-2.pdf. Acesso em: 21 maio 2018.

G1. (2017).PIB recua 3,6\% em 2016, e Brasil tem pior recessão da história. Disponível em:https://g1.globo.com/economia/noticia/pib-brasileiro-recua-36-em-2016-e-tem-pior-recessaoda-historia.ghtml. Acesso em: 05 maio 2018.

HARVEY, David.Condição pós-moderna: uma pesquisa sobre as origens da mudança cultural. 17.ed. São Paulo: Edições Loyola, 2008.

INSTITUTO DE PESQUISA DATAFOLHA. (2017).Avaliação da Reforma Trabalhista (PO813916). São Paulo, 26 e 27 de abril de 2017. Disponível em:

http://datafolha.folha.uol.com.br/opiniaopublica/2017/05/1880398-maioria-rejeita-reformatrabalhista.shtml. Acesso em: 15 maio 2018.

LENZA, Pedro. "Poder Legislativo". In: . Direito constitucional esquematizado. 19. ed. São Paulo: Saraiva, 2013, p. 861-1112.

NEXO JORNAL. (2017a).Por reforma, Temer libera verba via emenda. Como funciona essa lógica de governabilidade. Disponível em: https://www.nexojornal.com.br/expresso/2017/04/11/Por-reforma-Temer-libera-verba-viaemenda.-Como-funciona-essa-lógica-de-governabilidade. Acesso em:07 maio 2018.

. (2017b).Quais os fatores em jogo na análise da reforma trabalhista pelo Senado.

Disponível em:https://www.nexojornal.com.br/expresso/2017/05/02/Quais-os-fatores-em-jogona-an\%C3\%A1lise-da-reforma-trabalhista-pelo-Senado. Acesso em: 07 maio 2018.

OLIVEIRA, Adriano. “Análise de Conjuntura: conceito e aplicações”. Em Debate, v. 6, n. 1, mar. 2014, p. 24-35.

QUEIROZ, Antônio Augusto.Análise da conjuntura: como e por que fazê-la. Brasília, DF: DIAP, 2015.

SILVA, Luiz Eduardo Prates. (2014). "Metodologia de análise de conjuntura”. Estudos Teológicos, v. 28, n. 3, p. 305-315. Disponível em: 
http://periodicos.est.edu.br/index.php/estudos_teologicos/article/download/1171/1134. Acesso em: 18 abr. 2018.

SOUTO MAIOR, Jorge Luiz. (2017a).A CLT é velha. Disponível em http://www.jorgesoutomaior.com/blog/a-quem-interessa-essa-reforma-trabalhista. Acesso em: 25 maio 2018.

(2017b).A quem interessa essa "reforma" trabalhista? Disponível em:

http://www.jorgesoutomaior.com/blog/a-quem-interessa-essa-reforma-trabalhista.Acesso em: 25 maio 2018.

SOUZA, Herbert José de.Como se faz análise de conjuntura. 31.ed. Petrópolis: Vozes, 2009.

UOL ECONOMIA. (2017).STF investiga relator da reforma por relação com terceirizada fraudulenta.Disponível em: https://economia.uol.com.br/noticias/redacao/2017/04/26/stfinvestiga-relator-da-reforma-por-relacao-com-terceirizada-fraudulenta.htm. Acesso em: 15 maio 2018. 